\title{
Similar risk of cardiovascular events in idiopathic inflammatory myopathy and rheumatoid arthritis in the first 5 years after diagnosis
}

\author{
Cristina Párraga Prieto ${ }^{1}$ (D) $\cdot$ Fowzia Ibrahim ${ }^{1} \cdot$ Richard Campbell $^{1} \cdot$ Hector Chinoy $^{2,3} \cdot$ James Galloway $^{1}$. \\ Patrick Gordon ${ }^{1}$
}

Received: 6 March 2020 /Revised: 6 June 2020 / Accepted: 10 June 2020 / Published online: 22 June 2020

(C) The Author(s) 2020

\begin{abstract}
Objectives To estimate the incidence of cardiovascular (CV) events in idiopathic inflammatory myopathy (IIM) compared to patients with rheumatoid arthritis (RA) and the general population. To explore the contribution of traditional CV risk factors to any difference observed.

Methods A retrospective matched population-based cohort study was conducted using UK Clinical Practice Research Datalink (CPRD) from 1987 to 2013. The incidence of CV events was calculated for each cohort over time and compared using Cox proportional hazards models. Multivariable analyses were used to adjust for traditional CV risk factors.

Results A total of 603 patients with IIM 4047 RA and 4061 healthy controls were included. The rate of CV events in IIM was significantly greater than healthy controls [hazard ratio (HR) 1.47 (95\% confidence interval (CI) 1.18-1.83)] and remained significant after adjustment for CV risk factors [HR 1.38 (95\% CI 1.11-1.72)]. Risk was similar between IIM and RA [HR 1.01 (95\% CI 0.78-1.31)]. The rate of myocardial infarction [HR 1.61 (95\% CI 1.27-2.04)] but not stroke [HR 0.92 (95\% CI 0.59-1.44)] was significantly greater in IIM compared to healthy controls. After the first 5 years, the rate of CV events for RA remained significantly greater compared to the control group, but appeared to return to that of the healthy controls in the IIM group.

Conclusion IIM is associated with an increased risk of CV events in the first 5 years after diagnosis similar to that of RA. Beyond 5 years, the risk appears to return to that of the general population in IIM but not RA.
\end{abstract}

Key Points

- The excess risk of cardiovascular events in IIM is similar to that found in RA.

- The excess risk of cardiovascular events is greatest in the first 5 years after diagnosis.

Keywords Atherosclerosis $\cdot$ Cardiovascular event $\cdot$ Dermatomyositis $\cdot$ Idiopathic inflammatory myopathy $\cdot$ Polymyositis

Cristina Párraga Prieto

cristina_parraga_prieto@outlook.es

1 Centre for Rheumatic Diseases, King's College London, London, UK

2 Rheumatology Department, Salford Royal NHS Foundation Trust, Manchester Academic Health Science Centre, Salford, UK

3 NIHR Manchester Biomedical Research Centre, Manchester Academic Health Science Centre, Manchester University NHS Foundation Trust, The University of Manchester, Manchester, UK

\section{Introduction}

It is well established that several connective tissue diseases and chronic inflammatory disorders are associated with an increased risk for cardiovascular disease (CVD) secondary to accelerated atherosclerosis, including systemic lupus erythematosus (SLE) [1], rheumatoid arthritis (RA) [2] and psoriasis [3]. Traditional risk factors for atherosclerotic vascular disease do not fully explain this increased CVD risk [4-6]. Chronic systemic inflammation is thought to play an important role in accelerating the atherosclerotic processes [7].

However, not all systemic autoimmune diseases carry the same burden. Notably, the risk appears to be greater in SLE 
compared to RA, likely due to differences in the immune response between these conditions [7].

The idiopathic inflammatory myopathies (IIM) dermatomyositis (DM) and polymyositis (PM) are a group of autoimmune conditions characterised by inflammation of skeletal muscle and frequently other organ systems. DM is distinguished from the other IIMs by its characteristic cutaneous features. The immune response in IIM appears more similar to that of SLE than RA; both are characterised by a relatively normal CRP and may be exacerbated or induced by anti-TNF therapy $[8,9]$. In common with SLE and in contrast to RA, a large proportion of IIM patients have raised type 1 interferon levels [10] with a predominant interferon- $\alpha$ gene signature [11]. Data suggest that type 1 interferon may play a role in the premature atherosclerosis seen in SLE [12].

The risk of arterial events and the excess mortality seen in IIM have been compared to that reported in other systemic rheumatic diseases such as RA, ankylosing spondylitis, SLE and systemic sclerosis. However, comparisons are difficult due to the heterogeneity of published articles, and very few population-based reports have been presented [13].

The aims of the study were to estimate incidence of CV events in adult IIM in the UK and compare with RA and general population controls. To assess the differential risk for myocardial infarct (MI) and stroke, as well as magnitude of risk over time, and if an excess risk were established, assess whether the excess risk can be explained by traditional risk factors.

\section{Materials and methods}

\section{Data source and study design}

We conducted a retrospective matched population-based cohort study using the UK Clinical Practice Research Datalink (CPRD) from 1987 to 2013. The CPRD is a governmental, not-for-profit research service, jointly funded by the NHS National Institute for Health Research (NIHR) and the Medicines and Healthcare products Regulatory Agency (MHRA), a part of the Department of Health. CPRD encompasses a large UK dataset with a coverage of $6.9 \%$ of UK population and extensively representative of the UK population in terms of age, sex and ethnicity [14]. It has been providing anonymised primary care records for public health research since 1987. In addition, CPRD is linked via a trusted third party (the Health and Social Care Information Centre) to other patient-level datasets from secondary care, diseasespecific registry data, socio-economic and mortality records [15]. Hospital Episode Statistics (HES) and UK Death Register were established for the analysis, which respectively provided hospitalisation data and copies of death certificates and ICD-10 codes for primary, secondary and contributory causes of death.
The CPRD has been extensively used for observational research, with numerous studies published in peer-reviewed journals. High validity of CPRD data has been also demonstrated for the study of morbidity, with a median of $89 \%$ for confirmed diagnoses [15].

\section{Patient cohorts}

Subjects with at least two consecutive read codes for DM or PM were included as the index cohort (first-ever and subsequent records). As case validation for rarer diseases is an important limitation of the CPRD, detailed validation of IIM was undertaken. Participants were classified as either unlikely, probable or definite for the IIM diagnosis, based upon clinical and laboratory features, performance of muscle biopsy and electromyography, and immunosuppressive therapy, independently by two of the authors (PG and $\mathrm{HC}$ ). Where disagreement occurred, the classification was agreed following a case discussion. All analyses were limited to probable and definite cases, only. We defined as "probable" those patients with more than one episode of IIM diagnosis recorded on the database (at least two consecutive records of IIM in the clinical or referral record over the study period), high ESR or/and CRP, high CK level, seen in Rheumatology clinic, high dose of steroids treatment and immunosuppressive therapy, and "definite" those with the previous mentioned characteristics in addition to muscle biopsy. Individuals with other autoimmune diseases or conditions that might provide a differential diagnosis for IIM and diagnosis made in those subjects < 18 years old were excluded from all groups. Cases of inclusion body myositis were not included.

Up to four RA patients and healthy subjects on the observational window were matched to each IIM patient (exposed patient) for age ( \pm 5 years) and gender, using the index date matching and based on the initial IIM case records. Cases of IIM who did not fulfil the validation criteria were excluded from all analyses but not their matched RA patient and healthy controls. RA subjects were identified with at least two read codes for the diagnosis, with a "first-ever" and subsequent record of RA in the clinical or referral records during the patient up-to-the date of registration and study period. Clinical and referral records included medical history events and secondary care information, respectively. The index dates of the exposed and RA patients were no more than five years apart. Healthy subjects were defined as those with no records of autoimmune rheumatological disease on CPRD, using the validated CPRD coding system. Participants of this group were set to be the index date of the exposed patient.

\section{Assessment of cardiovascular events}

The outcomes of interest were fatal and non-fatal first incident major cardiovascular events during the period of follow-up, 
including myocardial infarction, acute coronary syndrome (ACS), unstable angina or stroke (ischaemic and haemorrhagic cerebrovascular events). Medical codes of CPRD, ICD-9 410 and ICD-10 121 codes were used to identify the mentioned CV events. Patients with CV events and/or stroke prior to the diagnosis of the autoimmune disease (IIM or RA) were excluded for both analyses (CV event and stroke analysis). In our main analysis, the combined cardiovascular endpoint was identified using read codes in CPRD as well as linked data from the Office for National Statistics death register and also hospitalisation data from Hospital Episode Statistics. Secondary analyses considered outcomes for cardiac and stroke endpoints separately.

Comorbidity was based on medical records, coded using read codes of CPRD as per previous published studies [16]. Obesity was defined by the recorded diagnosis and/or body mass index on the CPRD database according to WHO categories. Concerning tobacco consumption, patients were classified as active smoker, ex-smoker and never-smoker, consistent with the CPRD classification criteria. With regard to steroids treatment, we included those patients who had ever been on oral or systemic glucocorticosteroids over the study period.

\section{Statistical analysis}

Kruskal-Wallis and Chi-square tests were used to assess significant differences in demographic variables and comorbid medical disorders between patients with IIM, RA and healthy controls, using the former test to compare those continuous variables and the latter for categorical variables between groups. The incidence of cardiovascular events was calculated for each cohort over time and compared using Cox proportional hazards models. The validity of the Cox models were tested graphically using Nelson Aalen plots. Multivariable analyses were used to adjust for traditional cardiac risk factors (age, gender, diabetes mellitus, hypertension and smoking). Multivariable analyses adjusted for a priori chosen confounders as follows: age, gender, smoking status, prior cardiovascular disease (including myocardial infarction, acute coronary syndrome, unstable angina or stroke) and diabetes. Acknowledging that statin use may lie on the causal pathway to IIM, adjustment for statins or hypercholesterolaemia was not performed. However, we did not consider removing all patients on statin treatment from the analysis due to the possibility of causing a selection bias. In addition, statin-induced myopathy is a small subpopulation of myositis and so unlikely to have a major impact.

\section{Results}

The initial search of the CPRD revealed 1013 subjects with at least two read codes for IIM. Review of these records excluded 199 as the diagnosis was deemed neither probable nor definite. A further 211 subjects were excluded due to other diagnoses (e.g. systemic sclerosis or polymyalgia rheumatica). In total, 603 subjects with IIM remained eligible for inclusion in the main analysis, 300 patients with DM (50\%) and 303 with PM (50\%). In addition, 4047 patients with RA and 4061 healthy controls were included. The baseline characteristics of these groups are shown in Table 1.

Patients diagnosed with IIM and RA were significantly older than controls within the expected range of difference ( \pm 5 years) and had significantly more traditional risk factors for cardiovascular disease (Table 1). There were significantly more current smokers $(p<0.0001)$ in the RA compared to the IIM group. There was more statin use $(p<0.0001)$ and hypertension $(p=0.025)$ in the IIM group compared to the RA group but otherwise no significant differences observed for the variables between these two groups. Of the healthy individuals, $12 \%$ had used glucocorticoids (Table 1).

The rate of cardiovascular events (Table 2) was higher in the IIM and RA cohort (2.9 and 2.7 per 100 patient years, respectively) compared to the control group (1.5 per 100 patient years). IIM and RA patients had significantly higher hazard ratio (HRs) for all cardiovascular events: age and gender adjusted [HR 1.47 (95\% CI 1.18-1.83)] for IIM and [HR 1.36 (95\% CI 1.22-1.52)] for RA. As expected, adjustment for baseline cardiovascular risk factors reduced both HRs but there remained a significant increased risk compared to the control group. An analysis limited to cardiac events showed similar results with significantly higher HRs for cardiac events for both IIM and RA, before and after adjustment for cardiovascular risk factors (Table 2). Analysis of stroke revealed no significant increased risk in IIM or RA patients compared to controls.

The adjusted overall risk for a cardiovascular event showed similar trends in IIM and RA groups [HR 1.38 (95\% CI 1.111.72) for IIM and HR 1.26 (95\% CI 1.12-1.41) for RA], with a non-significant difference between the two diseases.

An analysis of cardiovascular event rates over time is shown in Fig. 1. The median follow-up per person was 7 years. The hazard for cardiovascular events increased in all groups over time. The excess hazard in IIM was most apparent in the first 5 years, [adjusted HR 1.32 (95\% CI 0.90-1.95)], but then appeared to diminish in the 5-10 year period $[0.74(0.32$ 1.69)] and 10-15 year period [1.03 (0.57-1.84)]. In contrast, in RA patients, the difference in hazard was more stable over time: first 5 years [adjusted HR 1.22 (95\% CI 0.91-1.65)], 510 years $[1.22(0.92-1.63)]$ and $10-15$ years [1.31 (1.051.65)] (Table 3).

\section{Discussion}

In this large and retrospective population-based study, IIM was associated with an increased risk of developing a 
Table 1 Baseline characteristics

\begin{tabular}{|c|c|c|c|c|c|}
\hline Characteristic & $\begin{array}{l}\text { Controls } \\
n=4061\end{array}$ & $\begin{array}{l}\text { IIM patients } \\
n=603\end{array}$ & $P$ value* & $\begin{array}{l}\text { RA patients } \\
n=4047\end{array}$ & $P$ value** \\
\hline Age (years) & $52 \pm 16$ & $58 \pm 16$ & 0.0001 & $57 \pm 15$ & 0.0001 \\
\hline Female & $2567(63)$ & $386(64)$ & 0.703 & $2597(64)$ & 0.369 \\
\hline Current smoker & $1019(25)$ & $154(26)$ & 0.024 & $1446(36)$ & $<0.001$ \\
\hline Hypertension & $1352(33)$ & $253(42)$ & $<0.001$ & $1506(37)$ & $<0.001$ \\
\hline Diabetes & $600(15)$ & $132(22)$ & $<0.001$ & $796(20)$ & $<0.001$ \\
\hline Statin therapy & 87 (2) & 109 (18) & $<0.001$ & $511(13)$ & $<0.001$ \\
\hline Obese & $317(8)$ & $70(12)$ & 0.002 & $415(10)$ & $<0.001$ \\
\hline $\mathrm{GC}$ at baseline & $476(12)$ & $433(67)$ & $<0.001$ & $2095(52)$ & $<0.001$ \\
\hline
\end{tabular}

Values are expressed as the mean $\pm \mathrm{SD}$ for age and $n(\%)$ for the rest of characteristics

IIM, idiopathic inflammatory myopathy; RA, rheumatoid arthritis; GC, Glucocorticoids at baseline

*IIM compared to control group; **RA compared to control group

cardiovascular event. Of note, the increased HR in the IIM cohort remained significant in multivariate analyses, suggesting that the excess risk early on cannot be explained entirely by traditional CV risk factors and suggests a role for inflammation in the increased CVD risk in IIM.

Previous studies have suggested an increased incidence of cardiovascular disease in myositis. In a study from Taiwan, 907 DM patients diagnosed from a national insurance claims database had an adjusted HR 3.37 for MI compared tocontrols in the first 2 years [17]. However, this study did not exclude patients with other connective tissue diseases or validate the diagnosis beyond the ICD code; perhaps for these reasons, the incidence of DM was over twice that described for all IIM in another Taiwanese study [18]. A Swedish study looked at patients hospitalised for autoimmune disease in Sweden; the standardised incident ratio for subsequent hospitalisation for coronary heart disease was 3.81 in the first year, also higher than our estimates. Nevertheless, again this study did not exclude patients with other connective tissue diseases or validate the diagnosis beyond the ICD code. In addition, the study assessed patients with severe disease requiring hospital admission [19]. A further study of 607 Canadian IIM patients, which

Table 2 Cardiovascular risk in myositis cohort compared to rheumatoid arthritis and healthy controls

\begin{tabular}{|c|c|c|c|}
\hline Outcome & IIM cohort & RA cohort & Controls \\
\hline \multicolumn{4}{|l|}{ Any $\mathrm{CV}^{1}$ Event } \\
\hline Number of patients & 94 & 700 & 652 \\
\hline Exposure (years) & 3244 & 25,785 & 42,871 \\
\hline Incidence $^{2}(95 \% \mathrm{CI})$ & $2.90(2.37-3.54)$ & $2.71(2.52-2.92)$ & $1.52(1.41-1.64)$ \\
\hline Unadjusted HR (95\%CI) & $1.47(1.18-1.83)$ & $1.36(1.22-1.52)$ & Ref \\
\hline Adjusted $\mathrm{HR}^{3}(95 \% \mathrm{CI})$ & $1.38(1.11-1.72)$ & $1.26(1.12-1.41)$ & Ref \\
\hline \multicolumn{4}{|l|}{ Myocardial infarction } \\
\hline Number of patients & 82 & 559 & 482 \\
\hline Exposure (years) & 3287 & 26,545 & 43,823 \\
\hline Incidence $^{2}(95 \% \mathrm{CI})$ & $2.49(2.01-3.10)$ & $2.11(1.94-2.30)$ & $1.10(1.01-1.20)$ \\
\hline Unadjusted HR (95\%CI) & $1.73(1.37-2.20)$ & $1.47(1.29-1.67)$ & Ref \\
\hline Adjusted $\mathrm{HR}^{3}(95 \% \mathrm{CI})$ & $1.61(1.27-2.04)$ & $1.36(1.19-1.54)$ & Ref \\
\hline \multicolumn{4}{|l|}{ Stroke } \\
\hline Number of patients & 21 & 209 & 241 \\
\hline Exposure (years) & 3554 & 28,323 & 46,114 \\
\hline Incidence $^{2}(95 \% \mathrm{CI})$ & $0.59(0.39-0.91)$ & $0.73(0.64-0.84)$ & $0.52(0.46-0.59)$ \\
\hline Unadjusted HR (95\%CI) & $0.92(0.59-1.44)$ & $1.11(0.91-1.34)$ & Ref \\
\hline Adjusted $\mathrm{HR}^{3}(95 \% \mathrm{CI})$ & $0.88(0.56-1.39)$ & $1.06(0.87-1.29)$ & Ref \\
\hline
\end{tabular}

IIM, idiopathic inflammatory myopathy; RA, rheumatoid arthritis

${ }^{1}$ Cardiovascular event (CV); ${ }^{2}$ Incidence per 100 person-time; ${ }^{3}$ Adjusted hazard ratio (HR) for age, gender, diabetes, hypertension, smoking status 
Fig. 1 Cardiovascular events over time

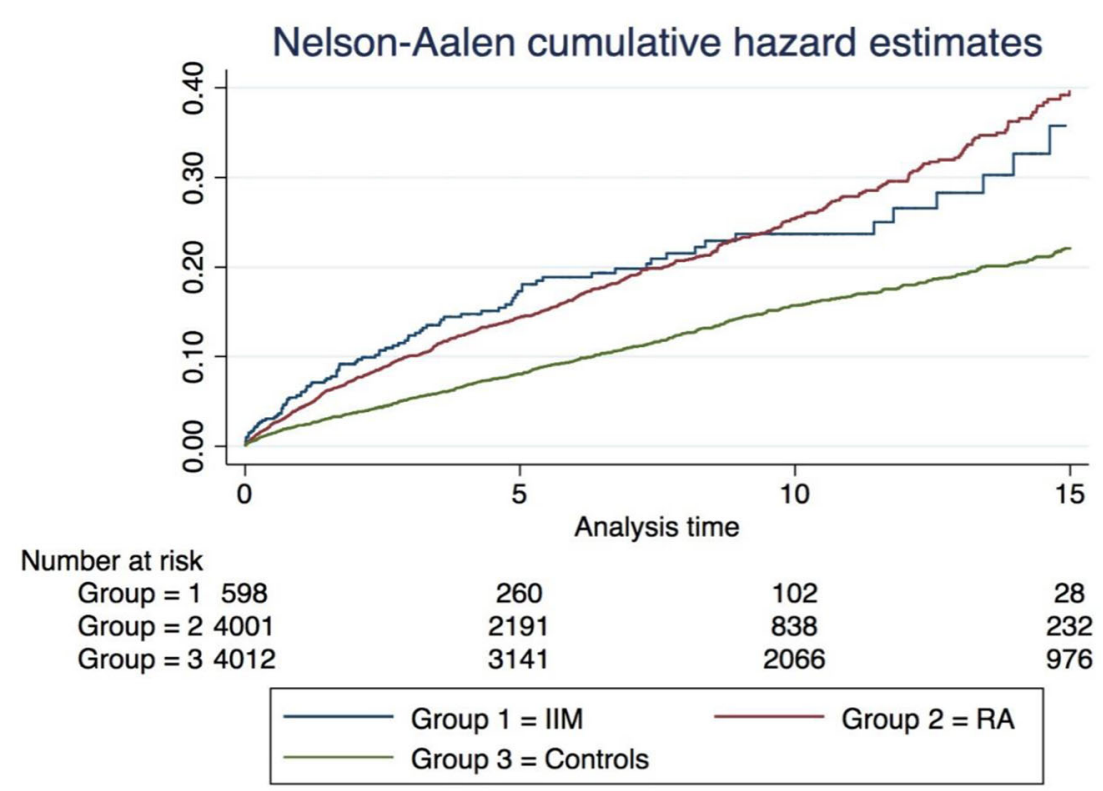

used billing, hospitalisation and pharmacy databases, had slightly more stringent inclusion criteria and had an age- and sex-adjusted standardised incident ratio compared to the normal population of 1.95, more in keeping with our findings [20]. A study from British Columbia which used ICD codes alone to validate cases, identified 774 new cases of IIM over 14 years in a population of 4.7 million, over twice the expected figure [21]. They reported a HR for MI of 3.89 for PM, 2.92 for DM and non-increased risk for ischaemic stroke in IIM. This study showed similar, but not significant trends between the increased risk for MI and stroke in DM and PM patients compared to the general population. A smaller number of outcomes was reported as the possible reason for their results. Another hypothesis of the discrepancy between our results and other studies is the inclusion of ischaemic and haemorrhagic stroke in our analysis instead of just ischaemic

Table 3 Cardiovascular event rates over time

\begin{tabular}{|c|c|c|c|}
\hline Time window & IIM & $\mathrm{RA}$ & Controls \\
\hline \multicolumn{4}{|l|}{ First 5 years } \\
\hline Number of patients & 74 & 464 & 292 \\
\hline Exposure (years) & 1972 & 15,407 & 15,407 \\
\hline Incidence $^{1}(95 \% \mathrm{CI})$ & $3.75(2.99-4.71)$ & $3.01(2.75-3.30)$ & $1.63(1.45-1.82)$ \\
\hline Unadjusted HR (95\%CI) & $1.72(1.33-2.22)$ & $1.34(1.18-1.59)$ & Ref \\
\hline Adjusted $\mathrm{HR}^{2}(95 \% \mathrm{CI})$ & $1.32(0.90-1.95)$ & $1.22(0.91-1.65)$ & Ref \\
\hline \multicolumn{4}{|l|}{ Second 5 years } \\
\hline Number of patients & 6 & 97 & 94 \\
\hline Exposure (years) & 504 & 4119 & 6548 \\
\hline Incidence $^{1}(95 \% \mathrm{CI})$ & $1.19(0.53-2.65)$ & $2.35(1.93-2.87)$ & $1.43(1.17-1.76)$ \\
\hline Unadjusted HR (95\%CI) & $0.77(0.34-1.75)$ & $1.39(1.05-1.85)$ & Ref \\
\hline Adjusted $\mathrm{HR}^{2}(95 \% \mathrm{CI})$ & $0.74(0.32-1.69)$ & $1.22(0.92-1.63)$ & Ref \\
\hline \multicolumn{4}{|l|}{ Third 5 years } \\
\hline Number of patients & 12 & 128 & 199 \\
\hline Exposure (years) & 682 & 5555 & 14,015 \\
\hline Incidence $^{1}(95 \% \mathrm{CI})$ & $1.76(1.00-3.10)$ & $2.30(1.94-2.74)$ & $1.42(1.24-1.63)$ \\
\hline Unadjusted HR (95\%CI) & $1.08(0.60-1.94)$ & $1.43(1.14-1.79)$ & Ref \\
\hline Adjusted $\mathrm{HR}^{2}(95 \% \mathrm{CI})$ & $1.03(0.57-1.84)$ & $1.31(1.05-1.65)$ & Ref \\
\hline
\end{tabular}

IIM, idiopathic inflammatory myopathy; $R A$, rheumatoid arthritis

${ }^{1}$ Incidence per 100 person-time; ${ }^{2}$ Adjusted hazard ratio (HR) for age, gender, diabetes, hypertension, smoking status 
cerebrovascular events $[17,22,23]$. The limitation of stroke event ascertainment may have also contributed to our findings.

In previous large meta-analyses, rheumatoid arthritis has been associated with a $48 \%$ increased risk of cardiovascular events (relative risk 1.48, 95\% CI 1.36-1.62) compared with the general population [24]. We compared the incidence of $\mathrm{CV}$ events in IIM with controls and RA, enabling comparison of the incidence with more a studied disease, providing an anchor point for the data and internal validation. Although the adjusted overall risk for a cardiovascular event was slightly greater for IIM than for RA in our study, the difference was small and not significant. As IIM may occur in association with other connective tissue diseases including SLE and systemic sclerosis, we excluded patients with additional diagnoses of connective tissue disease. Due to the data available on the CPRD, we were also able to be more stringent in our case assignment. As a result of this approach, we identified fewer than expected cases which may have led to an unexpected case selection bias and reduced the power of the study. This might have contributed to the difference between the excess of increased CV risk seen in IIM patients in comparison with RA cohort in our research. However, it also highlights the complexity of autoimmune diseases in their pathogenesis, with common factors in their aetiology but different mechanisms of autoimmunity.

Notably, whilst the HR for a cardiovascular event in RA was fairly stable across the 15 -year period after diagnosis, the risk for IIM varied markedly over time. The HR was increased in IIM compared to RA and healthy controls in the first 5 years but subsequently appeared to return to that of the general population. Similar results have been suggested in prior IIM studies, in particular, beyond the first year follow-up [25]. Rai et al. also reported a significant attenuation of the cardiovascular risk in the 5 years following the PM diagnosis, not seen in the DM group [21]. These results would be more in keeping with the observed perivascular changes, endothelial damage and myocardial involvement of IIM rather than the traditional pattern of premature atherosclerosis.

Disease activity is a predictor of cardiovascular disease in many inflammatory diseases including RA and SLE [26-28]. If the same is true for IIM, one might hypothesise that disease activity is greatest in the first 5 years subsequently settling with the CV risk following suit. Nevertheless, whilst the disease is perhaps likely to be at its most inflammatory in the initial stages, the limited literature available to date does not suggest a resolution of the inflammation after 5 years. Over a 20 -year period, Sultan and colleagues reported that $67.5 \%$ of the surviving patients in their cohort had a chronic relapsingremitting course or chronic progressive disease, with only $17.5 \%$ going into complete remission [29]. In juvenile dermatomyositis (JDM), Sanner and colleagues reported that after 16.8 years, $51-73 \%$ of JDM patients still had active disease
[30]. Whilst steroid use is almost universal in the initial management of both rheumatoid and IIM, the initial dosage is generally much higher in IIM and is a potential cause for the higher initial CVD risk in IIM patients.

A further possibility is that in the early stages of IIM, raised troponin levels either due to myocarditis or a high creatine kinase may lead to the incorrect diagnosis of a non-ST elevation myocardial infarct $[31,32]$. This might lead to false highrecorded MI event rates. In keeping with this hypothesis, a cardiac MR study showed $62 \%$ of an IIM cohort had inflammatory cardiac lesions [33]. However, the results need to be interpreted in the context of the CPRD data limitations.

There are a number of limitations associated with our study. Case ascertainment bias and also survivorship bias, which may impact on event rates over time, cannot be excluded as partial explanations for the findings observed. In addition, there was significant attrition in numbers over the later periods (from 5 to 10 and 10 to 15 years) which affected the power of our study in these periods of time.

Our database is UK only and therefore might be subject to bias relating to the UK population, including local prescribing and treatment practices for this condition which could impact on cardiac risk. Notably, a high proportion of the healthy individuals (12\%) included in our study had used glucocorticoids. In comparison, a previous CPRD study of the use of oral corticosteroids in the UK [34] reported a prevalence of oral corticosteroid treatment in the total adult CPRD population of $0.9 \%$, increasing up to $2.5 \%$ in the elderly population. In the vast majority of the cases, the indication of that therapy was due to respiratory disease, being prescribed by the General Practitioners of which prescriptions are automatically collected on the CPRD. As such, these results may not be generalisable to other IIM populations.

Further studies, ideally in large well-characterised prospective cohort, are required to confirm the reduction of the cardiovascular risk following 5 years the initial IIM diagnosis and to ensure that the events early in the disease are atherosclerotic rather than inflammatory.

In conclusion, our study demonstrated an excess of cardiovascular events in IIM of a similar order to that found in RA, with a greater excess risk during the first 5 years following the diagnosis. Consequently, guidelines on the assessment and management in IIM need to be developed to take into account cardiovascular risk in IIM. This would help reduce mortality in IIM which remains high $[35,36]$ despite immunosuppressive treatment, with cardiac disease being a major cause of death [37-39].

Funding information This work was supported by the Medical Research Council (grant number MR/N003322/1). The views expressed in this publication are those of the authors and not necessarily those of the NHS, the National Institute for Health Research or the Department of Health. 


\section{Compliance with ethical standards}

Disclosures None.

Ethical Approval Approval for the study was granted by the CPRD Independent Scientific Advisory Committee (ISAC 13_1377R).

Open Access This article is licensed under a Creative Commons Attribution 4.0 International License, which permits use, sharing, adaptation, distribution and reproduction in any medium or format, as long as you give appropriate credit to the original author(s) and the source, provide a link to the Creative Commons licence, and indicate if changes were made. The images or other third party material in this article are included in the article's Creative Commons licence, unless indicated otherwise in a credit line to the material. If material is not included in the article's Creative Commons licence and your intended use is not permitted by statutory regulation or exceeds the permitted use, you will need to obtain permission directly from the copyright holder. To view a copy of this licence, visit http://creativecommons.org/licenses/by/4.0/.

\section{References}

1. Skaggs BJ, Hahn BH, McMahon M (2012) Accelerated atherosclerosis in patients with SLE-mechanisms and management. Nat Rev Rheumatol 8(4):214-223

2. Skeoch $\mathrm{S}$, Bruce IN (2015) Atherosclerosis in rheumatoid arthritis: is it all about inflammation? Nat Rev Rheumatol 11(7):390-400

3. Gelfand JM, Neimann AL, Shin DB, Wang X, Margolis DJ, Troxel $\mathrm{AB}$ (2006) Risk of myocardial infarction in patients with psoriasis. JAMA. 296(14):1735-1741

4. Esdaile JM, Abrahamowicz M, Grodzicky T, Li Y, Panaritis C, du Berger R, Côte R, Grover SA, Fortin PR, Clarke AE, Senécal JL (2001) Traditional Framingham risk factors fail to fully account for accelerated atherosclerosis in systemic lupus erythematosus. Arthritis Rheum 44(10):2331-2337

5. del Rincón ID, Williams K, Stern MP, Freeman GL, Escalante A (2001) High incidence of cardiovascular events in a rheumatoid arthritis cohort not explained by traditional cardiac risk factors. Arthritis Rheum 44(12):2737-2745

6. Eder L, Chandran V, Gladman DD (2014) The Framingham risk score underestimates the extent of subclinical atherosclerosis in patients with psoriatic disease. Ann Rheum Dis 73(11):1990-1996

7. Fischer LM, Schlienger RG, Matter C, Jick H, Meier CR (2004) Effect of rheumatoid arthritis or systemic lupus erythematosus on the risk of first-time acute myocardial infarction. Am J Cardiol 93(2): 198-200

8. Studynkova JT, Mann H, Jarosova K et al (2014) A prospective, randomized, open-label, assessor-blind, multicenter study of efficacy and safety of combined treatment of methotrexate + glucocorticoids versus glucocorticoids alone in patients with polymyositis and dermatomyositis (prometheus trial). Ann Rheum Dis 73(Suppl 2)

9. De Bandt M, Sibilia J, Le Loët X et al (2005) Systemic lupus erythematosus induced by anti-tumour necrosis factor alpha therapy: a French national survey. Arthritis Res Ther. 7(3):R545-R551

10. Higgs BW, Liu Z, White B, Zhu W, White WI, Morehouse C, Brohawn P, Kiener PA, Richman L, Fiorentino D, Greenberg SA, Jallal B, Yao Y (2011) Patients with systemic lupus erythematosus, myositis, rheumatoid arthritis and scleroderma share activation of a common type I interferon pathway. Ann Rheum Dis 70(11):2029 2036
11. Magro CM, Segal JP, Crowson AN, Chadwick P (2010) The phenotypic profile of dermatomyositis and lupus erythematosus: a comparative analysis. J Cutan Pathol 37(6):659-671

12. Somers EC, Zhao W, Lewis EE, Wang L, Wing JJ, Sundaram B, Kazerooni EA, McCune WJ, Kaplan MJ (2012) Type I interferons are associated with subclinical markers of cardiovascular disease in a cohort of systemic lupus erythematosus patients. PLoS One 7(5): e37000

13. Vincze M, Dér H, Kerekes G et al (2014) Decreased flow-mediated dilatation with increased arterial stiffness and thickness as early signs of atherosclerosis in polymyositis and dermatomyositis patients. Clin Rheumatol 33(11):1635-1641

14. Herrett E, Gallagher AM, Bhaskaran K, Forbes H, Mathur R, van Staa T, Smeeth L (2015) Data resource profile: clinical practice research Datalink (CPRD). Int J Epidemiol 44(3):827-836

15. Herrett E, Thomas SL, Schoonen WM, Smeeth L, Hall AJ (2010) Validation and validity of diagnoses in the general practice research database: a systematic review. Br J Clin Pharmacol 69:4-14

16. Abhishek A, Nakafero G, Kuo CF, Mallen C, Zhang W, Grainge MJ, Doherty M (2018) Rheumatoid arthritis and excess mortality: down but not out. A primary care cohort study using data from clinical practice research Datalink. Rheumatology (Oxford) 57(6): 977-981

17. Lai YT, Dai YS, Yen MF, Chen LS, Chen HH, Cooper RG, Pan SL (2013) Dermatomyositis is associated with an increased risk of cardiovascular and cerebrovascular events: a Taiwanese population-based longitudinal follow-up study. Br J Dermatol 168(5):1054-1059

18. Yu KH, See LC, Kuo CF, Chou IJ, Chou MJ (2013) Prevalence and incidence in patients with autoimmune rheumatic diseases: a nationwide population-based study in Taiwan. Arthritis Care Res (Hoboken) 65(2):244-250

19. Zöller B, Li X, Sundquist J, Sundquist K (2012) Risk of subsequent coronary heart disease in patients hospitalized for immunemediated diseases: a nationwide follow-up study from Sweden. PLoS One 7(3):e33442

20. Tisseverasinghe A, Bernatsky S, Pineau CA (2009) Arterial events in persons with dermatomyositis and polymyositis. J Rheumatol 36(9):1943-1946

21. Rai SK, Choi HK, Sayre EC, Aviña-Zubieta JA (2016) Risk of myocardial infarction and ischaemic stroke in adults with polymyositis and dermatomyositis: a general population-based study. Rheumatology (Oxford) 55(3):461-469

22. Finsterer J, Stöllberger C (2010) Stroke in myopathies. Cerebrovasc Dis 29:6-13

23. Finsterer J (2012) Stroke and stroke-like episodes in muscle disease. Open Neurol J 6:26-36

24. England BR, Thiele GM, Anderson DR, Mikuls TR (2018) Increased cardiovascular risk in rheumatoid arthritis: mechanisms and implications. BMJ 361:k1036. https://doi.org/10.1136/bmj. k1036

25. Schwartz T, Diederichsen LP, Lundberg IE, Sjaastad Iand Sanner H (2016) Cardiac involvement in adult and juvenile idiopathic inflammatory myopathies. RMD Open 2(2):e000291

26. Magder LS, Petri M (2012) Incidence of and risk factors for adverse cardiovascular events among patients with systemic lupus erythematosus. Am J Epidemiol 176(8):708-719

27. Peters MJ, Symmons DP, McCarey D, Dijkmans BA, Nicola P, Kvien TK, McInnes I, Haentzschel H, Gonzalez-Gay MA, Provan S, Semb A, Sidiropoulos P, Kitas G, Smulders YM, Soubrier M, Szekanecz Z, Sattar N, Nurmohamed MT (2010) EULAR evidence-based recommendations for cardiovascular risk management in patients with rheumatoid arthritis and other forms of inflammatory arthritis. Ann Rheum Dis 69(2):325-331

28. Innala L, Möller B, Ljung L, Magnusson S, Smedby T, Södergren A, Öhman ML, Rantapää-Dahlqvist S, Wållberg-Jonsson S (2011) 
Cardiovascular events in early RA are a result of inflammatory burden and traditional risk factors: a five year prospective study. Arthritis Res Ther 13(4):R131

29. Sultan SM, Ioannou Y, Moss K, Isenberg DA (2002) Outcome in patients with idiopathic inflammatory myositis: morbidity and mortality. Rheumatology (Oxford) 41(1):22-26

30. Sanner H, Sjaastad I, Flatø B (2014) Disease activity and prognostic factors in juvenile dermatomyositis: a long-term follow-up study applying the Paediatric rheumatology international trials organization criteria for inactive disease and the myositis disease activity assessment tool. Rheumatology (Oxford) 53(9):1578-1585

31. Hughes M, Lilleker JB, Herrick AL, Chinoy H (2015) Cardiac troponin testing in idiopathic inflammatory myopathies and systemic sclerosis-spectrum disorders: biomarkers to distinguish between primary cardiac involvement and low-grade skeletal muscle disease activity. Ann Rheum Dis 74(5):795-798

32. Lilleker JB, Diederichsen ACP, Jacobsen S, Guy M, Roberts ME, Sergeant JC, Cooper RG, Diederichsen LP, Chinoy H (2018) Using serum troponins to screen for cardiac involvement and assess disease activity in the idiopathic inflammatory myopathies. Rheumatology (Oxford) 57(6):1041-1046

33. Rosenbohm A, Buckert D, Gerischer N, Walcher T, Kassubek J, Rottbauer W, Ludolph AC, Bernhardt P (2015) Early diagnosis of cardiac involvement in idiopathic inflammatory myopathy by cardiac magnetic resonance tomography. J Neurol 262(4):949-956
34. Van Staa TP, Leufkens HGM, Abenhaim L, Begaud B, Zhang B, Cooper C (2000) Use of oral corticosteroids in the United Kingdom. QJM 93(2):105-111

35. Lundberg IE, Forbess CJ (2008) Mortality in idiopathic inflammatory myopathies. Clin Exp Rheumatol 26(5 Suppl 51):S109-S114

36. Gupta R, Wayangankar SA, Targoff IN, Hennebry TA (2011) Clinical cardiac involvement in idiopathic inflammatory myopathies: a systematic review. Int J Cardiol 148(3):261-270

37. Zhang L, Wang GC, Ma L, Zu N (2012) Cardiac involvement in adult polymyositis or dermatomyositis: a systematic review. Clin Cardiol 35(11):686-691

38. Bazzani C, Cavazzana I, Ceribelli A, Vizzardi E, Dei Cas L, Franceschini F (2010) Cardiological features in idiopathic inflammatory myopathies. J Cardiovasc Med (Hagerstown) 11(12):906911

39. Linos E, Fiorentino D, Lingala B, Krishnan E, Chung L (2013) Atherosclerotic cardiovascular disease and dermatomyositis: an analysis of the Nationwide inpatient sample survey. Arthritis Res Ther 15(1):R7

Publisher's note Springer Nature remains neutral with regard to jurisdictional claims in published maps and institutional affiliations. 